\title{
АПРОБАЦИЯ РУССКОЯЗЫЧНОЙ ВЕРСИИ ОПРОСНИКА КОГНИТИВНОЙ И АФФЕКТИВНОЙ ЭМПАТИИ
}

\author{
M.A. ОКАТОВА \\ ${ }^{a}$ Московский государственныгй университет имени М.В. Ломоносова, 119991, Россия, Москва, \\ Ленинские горы, д. 1
}

\section{Approbation of the Russian Version of the Questionnaire of Cognitive and Affective Empathy}

\author{
M.A. Okatova ${ }^{a}$ \\ ${ }^{a}$ Lomonosov Moscow State University, 1 Leninskie Gory, Moscow, 119991, Russian Federation
}

\begin{abstract}
Резюме
В статье представлены результаты апробации Опросника когнитивной и аффективной эмпатии Р. Реньерс на русскоязычной выборке. В отличие от других направленных на диагностику эмпатии методик, доступных русскоязычному исследователю, данный опросник демонстрирует хорошие психометрические показатели, а также пригоден для измерения как когнитивной, так и аффективной эмпатии. В исследовании приняли участие 788 человек в возрасте от 18 до 66 лет $(\mathrm{M}=26, \mathrm{SD}=10.1 ; 707$ женщин и 81 мужчина). Методом конфирматорного факторного анализа была подтверждена заявленная в оригинальной версии опросника факторная структура, обе проверенные модели демонстрируют удовлетворительный уровень соответствия данным. Шкалы методики показывают высокие значения надежности-согласованности, составляющие их субшкалы - удовлетворительные значения надежностисогласованности. Конвергентная валидность подтверждается наличием корреляций со шкалами эмоционального интеллекта, психопатии, макиавеллизма. Когнитивная эмпатия положительно связана со всеми субшкалами эмоционального интеллекта, аффективная
\end{abstract}

\begin{abstract}
The article presents the results of approbation of the Questionnaire of Cognitive and Affective Empathy in Russia. Unlike other methods aimed at diagnosing empathy available to a Russian-speaking researcher, this questionnaire demonstrates good psychometric properties and is suitable for measuring both cognitive and affective empathy. 788 participants aged $18-66(\mathrm{M}=26$, $\mathrm{SD}=10.1 ; 707$ females и 81 males) took part in the study. Confirmatory factor analyses supported the factor structure of the original QCAE, both models tested demonstrate acceptable goodness of fit indices. Its scales showed good internal consistency, its subscales demonstrated satisfactory internal consistency. Convergent validity is confirmed by correlations with scales of emotional intelligence, psychopathy, Machiavellianism. Cognitive empathy correlated positively with all subscales of emotional intelligence, affective empathy correlated positively with interpersonal emotional intelligence, but negatively with intrapersonal emotional intelligence. Psychopathy and Machiavellianism correlated negatively with affective empathy
\end{abstract}


эмпатия положительно связана с межличностным эмоциональным интеллектом, но отрицательно - с внутриличностным эмоциональным интеллектом. Психопатия и макиавеллизм отрицательно связаны с аффективной эмпатией и одной из субшкал когнитивной эмпатии. Женщины демонстрируют более высокий уровень аффективной эмпатии, чем мужчины, гендерных различий в уровне когнитивной эмпатии выявлено не было. Полученные результаты позволяют рассматривать предложенную версию методики в качестве инструмента оценки когнитивной и аффективной эмпатии. Наличие надежного и валидного русскоязычного инструмента диагностики эмпатии может расширить возможности практической и исследовательской деятельности, в том числе кросс-культурных исследований.

Ключевые слова: эмпатия, когнитивная эмпатия, аффективная эмпатия, QCAE, эмоциональный интеллект, Темная триада.

Окатова Мария Александровна - аспирант, кафедра возрастной психологии, факультет психологии, МГУ имени М.В. Ломоносова. Сфера научных интересов: психометрика, эмпатия, детско-родительские отношения. Контакты: maokatova@mail.ru and one subscale of cognitive empathy. The levels of affective empathy were found to be higher in women than men; no gender differences in the levels of cognitive empathy were found. The results make it possible to consider the suggested version of the questionnaire as a tool for assessing cognitive and affective empathy. Russian version of QCAE can be used for future assessment of empathy in both clinical and research practice, including cross-cultural studies.

Keywords: empathy, cognitive empathy, affective empathy, QCAE, emotional intelligence, Dark Triad.

Maria A. Okatova - PhD student, Department of Developmental Psychology, Lomonosov Moscow State University.

Research Area: psychometrics, empathy, parent-child relationship.

E-mail: maokatova@mail.ru

\section{Введение}

Несмотря на многообразие определений, приписываемых понятию эмпатии, большинство исследователей сходятся на том, что эта способность играет значимую роль в межличностном взаимодействии. С высоким уровнем развития эмпатии связывают просоциальное поведение (Eisenberg, Miller, 1987; Lockwood et al., 2014), дружелюбие как один из факторов Большой пятерки (Graziano, Eisenberg, 1997), лидерство (Kellett et al., 2006). Дефицит способности к эмпатии наблюдается в ряде психических расстройств, таких как психопатия (Blair, 2005), расстройство аутистического спектра (Baron-Cohen, Wheelwright, 2004), шизофрения (Lee et al., 2004). Недостаток эмпатических способностей также связан с эмоциональной холодностью, агрессивным и антисоциальным поведением (Miller, Eisenberg, 1988).

Столь широкое распространение данного конструкта остро ставит задачу нахождения валидного и надежного инструмента для его измерения. Среди доступных отечественному исследователю методик на данный момент можно выделить «Многофакторный опросник эмпатии» М. Дэвиса (IRI; Davis, 
1983), апробация которого была выполнена коллективом автором относительно недавно (Карягина и др., 2013), и «Уровень сопереживания» С. Барон-Коэна и С. Уилрайта (EQ; Baron-Cohen, Wheelwright, 2004), также прошедший апробацию на русскоязычной выборке (Kosonogov, 2014). Оба опросника демонстрируют хорошие психометрические показатели и широко используются для измерения эмпатии, однако имеют некоторые ограничения. EQ содержит 60 вопросов, 20 из которых направлены на отвлечение респондента от содержания остальных вопросов, 40 - на измерение общего уровня эмпатии. Таким образом, получить информацию о выраженности когнитивного или аффективного компонентов эмпатии посредством данного опросника нельзя. IRI предоставляет подобную возможность: опросник содержит четыре шкалы, Эмпатическая забота и Личный дистресс направлены на измерение аффективного компонента эмпатии, Децентрация и Фантазия позволяют сделать вывод о выраженности ее когнитивного компонента. Ряд исследователей, однако, отмечают, что содержание вопросов шкалы Личного дистресса в большей степени отражает степень тревожности как личностного свойства, нежели степень эмпатического дистресса, вызванного эмоциями другого (Карягина, Придачук, 2017; Jolliffe, Farrington, 2004), тогда как шкала Фантазии в большей степени отражает способности, связанные с воображением, нежели эмпатические способности (Baron-Cohen, Wheelwright, 2004; Baldner, McGinley, 2014).

Среди русскоязычных исследователей также распространена методика диагностики эмпатических способностей В.В. Бойко. Опросник содержит шесть шкал, две из которых, согласно автору, дают возможность сделать вывод о выраженности у респондента эмоционального и рационального компонентов эмпатии. Ряд исследователей, однако, обращают внимание на отсутствие информации о психометрических характеристиках данной методики, а также на неоднозначность теоретических конструктов, на которые опирался автор при создании опросника (Карягина и др., 2013).

Одним из зарекомендовавших себя инструментов измерения эмпатии является созданный Р. Реньерс с коллегами «Опросник когнитивной и аффективной эмпатии» (QCAE; Reniers et al., 2011). Авторы сделали акцент на разделении когнитивной эмпатии, понимаемой как способность построить рабочую модель эмоциональных состояний других, и аффективной эмпатии, понимаемой как сензитивность к чувствам других и способность разделять эти чувства. Важность подобного разграничения определяется относительной независимостью двух компонентов эмпатии друг от друга, что подтверждается исследованиями развития эмпатии при патологиях и локализации этих процессов в головном мозге. Так, исследования, проведенные с участием лиц с психопатическими расстройствами, позволяют заключить, что для данной группы людей характерным является дефицит аффективной стороны эмпатии при сохранности когнитивного ее компонента (Jones et al., 2010; SearaCardoso et al., 2012). Обратная картина наблюдается у людей с расстройствами аутистического спектра: при сохранности эмоционального компонента эмпатии у них заметно слабее развит ее когнитивный компонент (Jones et al., 
2010; Rueda et al., 2015). Соотносятся с данной позицией и исследования, демонстрирующие различия в плотности серого вещества разных отделов головного мозга в зависимости от выраженности когнитивной или аффективной эмпатии (Banissy et al., 2012; Eres et al., 2015; Uribe et al., 2019) а также исследования, в которых показана разница в активации отделов головного мозга в зависимости от протекания того или иного эмпатического процесса (Kogler et al., 2020). Таким образом, многомерность данного конструкта делает актуальной задачу разработки такого инструмента, который позволит сделать вывод отдельно о каждом компоненте эмпатии.

При конструировании QCAE использовались утверждения, взятые из ряда зарекомендовавших себя опросников, в том числе EQ и IRI. Каждое утверждение оценивалось с точки зрения принятых авторами определений когнитивной и аффективной эмпатии, в случае согласованной оценки утверждение включалось в опросник. Первая версия QCAE составила 65 пунктов, после проведенного факторного анализа количество пунктов сократилось до 31 , выделенные факторы составили 5 субшкал. Способность к децентрации (Perspective Taking) позволяет оценить, насколько хорошо человеку удается определить, что чувствует другой; Склонность к децентрации (Online Simulation) в большей степени характеризует нацеленность человека на то, чтобы попытаться представить, как чувствует себя другой, вместе они составляют шкалу когнитивной эмпатии. Различие между этими двумя субшкалами иллюстрируется используемыми в вопросах глаголами: «легко могу», «быстро понимаю», «хорошо предугадываю», - которые применяются при оценке Способности к дещентрации, «стараюсь посмотреть», «пытаюсь представить» - при оценке Склонности к децентрации. Отзеркаливанию эмоций (Emotion Contagion) соответствует автоматическая реакция в ответ на чувства другого человека, характеризующаяся разделением этих чувств; Чувствительность к близким (Proximal Responsivity) позволяет оценить эмоциональную отзывчивость, сензитивность к чувствам ближайшего окружения человека; Общая чувствительность (Peripheral Responsivity) в большей степени оценивает сензитивность к чувствам персонажей фильмов или книг, эти три субшкалы вместе составляют шкалу аффективной эмпатии.

Опросник демонстрирует хорошие психометрические показатели, на данный момент существуют его апробации на итальянском (Giromini et al., 2016), французском (Myszkowski et al., 2017), португальском (Queirys et al., 2018) и китайском (Liang et al., 2019) языках. Общей целью данной работы является апробация его русскоязычной версии; к конкретным задачам нашего исследования относятся установление факторной структуры опросника, проверка надежности шкал и субшкал, входящих в него, проверка его конвергентной валидности.

\section{Метод}

Участники исследования. В исследовании приняли участие 788 человек в возрасте от 18 до 66 лет ( $\mathrm{M}=26, \mathrm{SD}=10.1 ; 707$ женщин и 81 мужчина), из них 
319 человек с высшим образованием, 254 человека с неоконченным высшим образованием, 136 человек со средним специальным образованием, 79 человек со средним образованием. Средние значения по возрасту для женщин $\mathrm{M}=25.5$, $\mathrm{SD}=9.6$, для мужчин $\mathrm{M}=30.1, \mathrm{SD}=13.2$, указанные различия статистически значимы ( $p<0.05)$. Выборка формировалось по принципу «снежного кома».

Опросник когнитивной и аффективной эмпатии. Опросник состоит из 31 утверждения и 5 субшкал, его заполнение предполагает использование 4-балльной шкалы, где 1 - полностью не согласен, 4 - полностью согласен. Помимо коэффициента общей эмпатии, опросник предполагает получение коэффициентов когнитивной (2 субшкалы) и аффективной (3 субшкалы) эмпатии.

Два психолога, свободно владеющие русским и английским языками, независимо друг от друга перевели текст опросника на русский язык. Из представленных вариантов с привлечением третьего независимого эксперта составили финальную версию перевода. Русскоязычный вариант опросника затем был передан на обратный перевод другому владеющему обоими языками специалисту. Обратный перевод был проверен и одобрен автором оригинального опросника.

Проверка конвергентной валидности опросника предполагает использование методик, измеряющих тот же конструкт, однако два наиболее зарекомендовавших себя в области измерения эмпатии опросника - IRI и $\mathrm{EQ}-$ были задействованы при создании QCAE. В связи с этим было решено включить в набор методик опросники, направленные на измерение схожих конструктов.

Опросник ЭмИн Д.В. Люсина. Опросник состоит из 46 утверждений, 5 субшкал, предполагает использование 4-балльной шкалы Лайкерта. Направлен опросник на измерение межличностного и внутриличностного эмоционального интеллекта, включает в себя следующие субшкалы: понимание чужих эмоций, управление чужими эмоциями, понимание своих эмоций, управление своими эмоциями, контроль экспрессии (Люсин, Ушаков, 2009).

Опросник «Темная дюжина». Опросник состоит из 12 утверждений, 3 шкал, его заполнение предполагает использование 5-балльной шкалы Лайкерта. Направлен опросник на измерение основных черт Темной триады, содержит следующие шкалы: макиавеллизм, психопатия, нарциссизм (Jonason, Webster, 2010). Русскоязычная версия опросника демонстрирует хорошие психометрические показатели (Корнилова и др., 2015).

У людей с выраженными чертами психопатии и макиавеллизма, как правило, наблюдается дефицит эмпатических способностей, что позволяет нам использовать опросник «Темная дюжина» в целях проверки конвергентной валидности QCAE.

\section{Результаты}

\section{Факторная структура и надежность}

Конфирматорный факторный анализ структуры опросника был проведен в программе EQS for Windows v. 6.4. В соответствии с исходной статьей авторов 
(Reniers et al., 2011) были проверены две модели: Модель 1, в которую были включены пять коррелирующих между собой факторов, и Модель 2, в которую, помимо пяти факторов, были включены два коррелирующих между собой фактора второго порядка (когнитивная и аффективная эмпатия).

Все корреляции пунктов со шкалами оказались значимы, однако значения факторных нагрузок пунктов 1 и 17 оказались недостаточно высокими (0.16 для обоих пунктов). Последующий анализ указанных вопросов продемонстрировал их теоретическую несостоятельность, в связи с чем было решено исключить их из русскоязычной версии опросника.

При построении моделей нами были изучены индексы модификации Лагранжа. В обе модели были внесены ковариации между остаточной дисперсией пунктов, вызванной схожестью формулировок вопросов (рисунок 1).

При оценке показателей соответствия мы опирались на следующие значения: CFI, TLI >0.95, SRMR < 0.08, RMSEA $<0.06$ (Hu, Bentler, 1999), $\chi^{2} / \mathrm{df}<5$ (Watkins, 1989). Представленные в таблице 1 показатели позволяют сделать вывод об удовлетворительном уровне соответствия данным обеих моделей. Модель 1, как и в оригинальном исследовании, продемонстрировала чуть более высокий уровень соответствия данным.

Рисунок 1

Факторная структура протестированных моделей: Модель 1 (слева), Модель 2 (справа).

Все коэффициенты значимы на уровне $p<0.05$
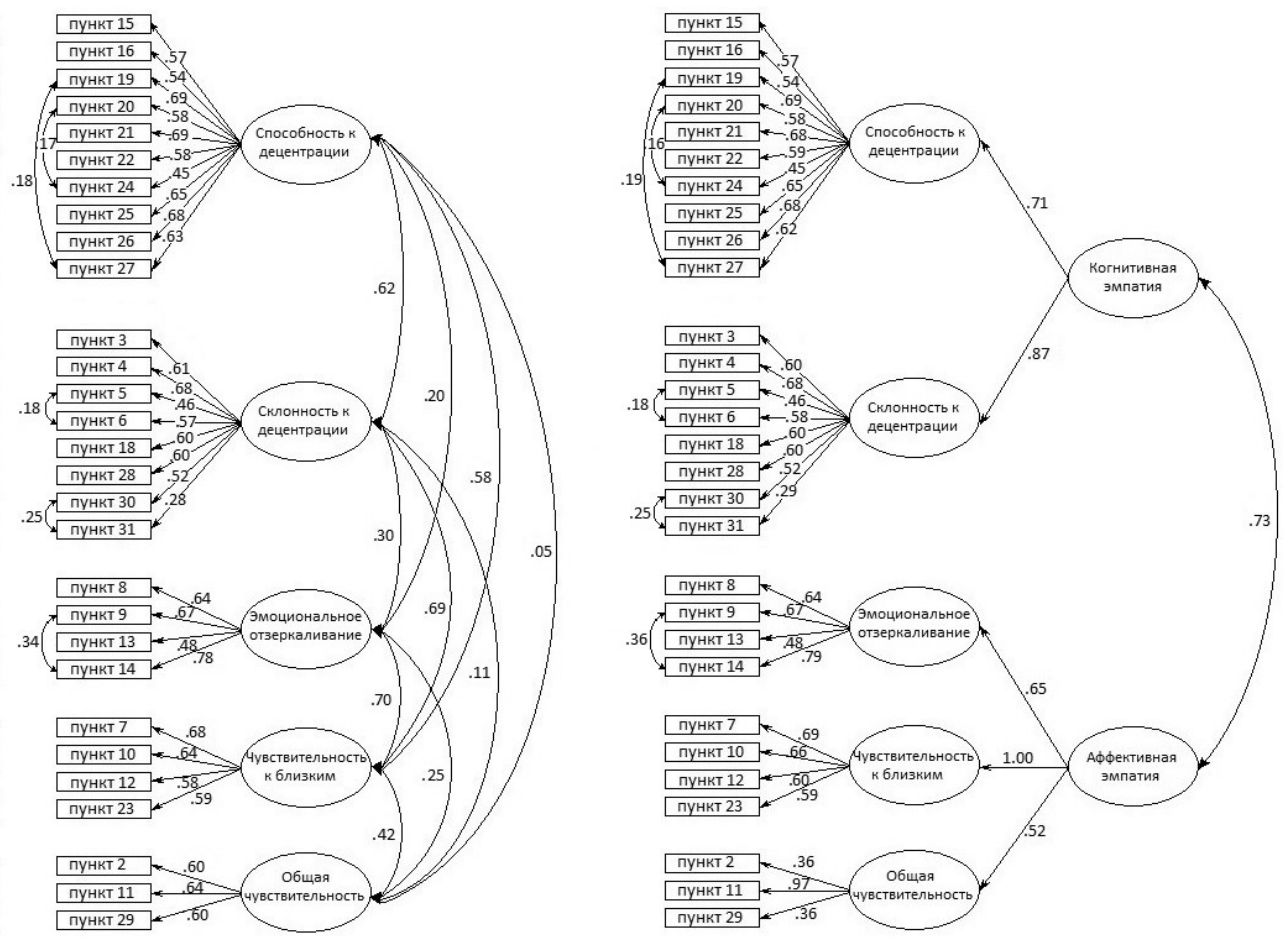
Таблица 1

Показатели соответствия протестированных моделей

\begin{tabular}{|c|c|c|c|c|c|c|c|c|}
\hline Модель & $\boldsymbol{\chi}^{\mathbf{2}}$ & $\mathbf{d f}$ & $\boldsymbol{\chi}^{\mathbf{2}} / \mathbf{d f}$ & $\mathbf{C F I}$ & SRMR & RMSEA & AIC & TLI \\
\hline 1 & 1202.91 & 362 & 3.32 & 0.953 & 0.071 & 0.054 & 478.9 & 0.948 \\
\hline 2 & 1267.93 & 361 & 3.51 & 0.950 & 0.071 & 0.056 & 545.9 & 0.943 \\
\hline
\end{tabular}

В результате анализа надежности опросника (с помощью IBM SPSS Statistics 23.0) были получены следующие коэффициенты внутренней согласованности а Кронбаха: Способность к децентрации - 0.86 , Склонность к децентрации - 0.77, Отзеркаливание эмоций - 0.72, Чувствительность к близким - 0.71, Общая чувствительность -0.64 . Коэффициенты для шкал когнитивной и аффективной эмпатии -0.86 и 0.78 соответственно.

Коэффициенты надежности $\omega$ Макдоналда для субшкал (подсчитанные с помощью пакета «psych» в R) также находятся в пределах удовлетворительных значений: Способность к децентрации - 0.87 , Склонность к децентрации 0.83 , Отзеркаливание эмоций -0.75 , Чувствительность к близким - 0.73 , Общая чувствительность -0.65 . Показатели для шкал когнитивной и аффективной эмпатии -0.89 и 0.83 .

\section{Конвергентная валидность}

Для оценки конвергентной валидности в качестве внешних критериев были использованы опросники ЭмИн и «Темная дюжина» (коэффициенты корреляций приведены в таблице 2).

Шкала Психопатии оказалась отрицательно связана со всеми компонентами эмпатии, кроме Способности к децентрации, наиболее сильной оказалась связь со шкалой Аффективной эмпатии $(r=-0.33, p<0.01)$. Шкала Макиавеллизма положительно связана со Способностью к децентрации, отрицательно - со Склонностью к децентрации, а также с Общей чувствительностью. Также были обнаружены очень слабые положительные связи между шкалой Нарциссизма и шкалами Способности к децентрации и Отзеркаливания эмоций.

Все субшкалы опросника ЭмИн оказались положительно связаны со шкалой Когнитивной эмпатии, наиболее сильной оказалась связь шкалы Понимания чужих эмоций и шкалы Способности к децентрации $(r=0.73, p<0.01)$. Также Понимание чужих эмоций - единственная шкала, по которой не наблюдается отрицательной связи с аффективной эмпатией или одним из ее компонентов.

\section{Гендерные различия}

В таблице 3 приведены средние значения и стандартные отклонения показателей шкал и субшкал опросника. Применение $t$-критерия для независимых 
Таблица 2

Анализ конвергентной валидности Опросника когнитивной и аффективной эмпатии

\begin{tabular}{|c|c|c|c|c|c|c|c|c|}
\hline & \multirow{2}{*}{$\begin{array}{c}\text { Общий } \\
\text { балл по } \\
\text { КАЭ }\end{array}$} & \multicolumn{3}{|c|}{ Когнитивная эмпатия } & \multicolumn{4}{|c|}{ Аффективная эмпатия } \\
\hline & & \begin{tabular}{|c} 
Общий \\
балл \\
\end{tabular} & СпД & СклД & $\begin{array}{c}\text { Общий } \\
\text { балл }\end{array}$ & ОЭ & ЧБ & $\mathrm{O \Psi}$ \\
\hline Макиавеллизм & -0.02 & 0.02 & $0.13^{* *}$ & $-0.13^{* *}$ & $-0.07^{*}$ & -0.01 & -0.07 & $-0.1^{* *}$ \\
\hline Психопатия & $-0.24^{* *}$ & $-0.12^{* *}$ & 0.00 & $-0.23 * *$ & $-0.33^{* *}$ & $-0.18^{* *}$ & $-0.3^{* *}$ & $-0.28 * *$ \\
\hline Нарциссизм & $0.12^{* *}$ & $0.1^{* *}$ & $0.16^{* *}$ & -0.01 & $0.11^{* *}$ & $0.18^{* *}$ & 0.04 & 0.01 \\
\hline $\begin{array}{l}\text { Понимание чужих } \\
\text { эмоций }\end{array}$ & $0.55^{* *}$ & $0.66^{* *}$ & $0.73^{* *}$ & $0.36^{* *}$ & $0.17 * *$ & 0.02 & $0.33^{* *}$ & 0.02 \\
\hline $\begin{array}{l}\text { Управление чужи- } \\
\text { ми эмоциями }\end{array}$ & $-0.24^{* *}$ & $0.32^{* *}$ & $0.41 * *$ & $0.11^{* *}$ & 0.01 & $-0.16^{* *}$ & $0.17^{* *}$ & 0.03 \\
\hline $\begin{array}{l}\text { Понимание своих } \\
\text { эмоций }\end{array}$ & 0.04 & $0.17^{* *}$ & $0.19^{* *}$ & $0.09 * *$ & $-0.18^{* *}$ & $-0.27^{* *}$ & -0.07 & -0.02 \\
\hline $\begin{array}{l}\text { Управление свои- } \\
\text { ми эмоциями }\end{array}$ & $0.1^{* *}$ & $0.26^{* *}$ & $0.28 * *$ & $0.16^{* *}$ & $-0.18^{* *}$ & $-0.27 * *$ & 0.00 & $-0.13^{* *}$ \\
\hline $\begin{array}{l}\text { Контроль экспрес- } \\
\text { сии }\end{array}$ & -0.05 & $0.12^{* *}$ & $0.1 * *$ & $0.11^{* *}$ & $-0.3^{* *}$ & $-0.3^{* *}$ & $-0.15^{* *}$ & $-0.22 * *$ \\
\hline
\end{tabular}

Примечание. КАЭ - Опросник когнитивной и аффективной эмпатии, СпД - Способность к децентрации, СклД - Склонность к децентрации, ОЭ - Отзеркаливание эмоций, ЧБ Чувствительность к близким, ОЧ - Общая чувствительность.

$* p<0.05, * * p<0.01$.

Таблица 3

Описательная статистика субшкал Опросника когнитивной и аффективной эмпатии

\begin{tabular}{|l|c|c|c|c|}
\hline \multirow{2}{*}{\multicolumn{1}{|c|}{ Шкалы }} & \multicolumn{2}{c|}{ Мужчины } & \multicolumn{2}{c|}{ Женщины } \\
\cline { 2 - 5 } & Среднее & Ст. откл. & Среднее & Ст. откл. \\
\hline Общий балл & 76.2 & 14.66 & 80.24 & 13.03 \\
\hline Когнитивная эмпатия & 47.1 & 10.85 & 47.73 & 9.34 \\
\hline Способность к децентрации & 26.54 & 6.98 & 26.78 & 6.06 \\
\hline Склонность к децентрации & 20.56 & 5.2 & 20.95 & 4.79 \\
\hline Аффективная эмпатия & 29.1 & 5.81 & 32.51 & 6.02 \\
\hline Отзеркаливание эмоций & 9.3 & 2.87 & 10.82 & 3.01 \\
\hline Чувствительность к близким & 10.96 & 2.99 & 11.96 & 2.85 \\
\hline Общая чувствительность & 8.83 & 2.21 & 9.74 & 2.15 \\
\hline
\end{tabular}

выборок позволяет сделать вывод о большей выраженности аффективной эмпатии и всех составляющих ее субшкал у женщин $(\mathrm{M}=32.5, \mathrm{SE}=0.23)$, чем у мужчин $(\mathrm{M}=29.1, \mathrm{SE}=0.65): t(786)=-4.85, p=0, d=0.83$. Значимых гендерных различий в показателях когнитивной эмпатии получено не было: $t(786)=-0.568, p=0.57, d=0.06$, при $\mathrm{M}=47.7, \mathrm{SE}=0.35$ у женщин и $\mathrm{M}=47.1$, 
$\mathrm{SE}=1.2$ у мужчин. Обнаруженные различия являются значимыми с учетом возраста в качестве ковариаты (при построении общей линейной модели).

\section{Обсуждение результатов}

В данном исследовании нами была апробирована русскоязычная версия Опросника когнитивной и аффективной эмпатии. Анализ факторной структуры опросника позволяет подтвердить предложенную авторами пятифакторную структуру методики, входящие в опросник шкалы характеризуются высоким уровнем надежности-согласованности и значимо коррелируют со шкалами других методик, направленных на измерение связанных с эмпатией конструктов. В целом эти результаты свидетельствуют о возможности использования Опросника когнитивной и аффективной эмпатии для диагностики эмпатических способностей.

Высокие значения факторных нагрузок были получены для всех пунктов опросника, кроме 17-го ( Мне трудно понять, почему некоторые вещи так сильно расстраивают людей»), составляющего часть субшкалы Общей чувствительности, и 1-го («Иногда мне бывает тяжело посмотреть на ситуацию с позиции другого человека»), входящего в субшкалу Склонности к децентрации. Низкий показатель факторной нагрузки для 17-го пункта наблюдался и при апробации опросника португальскими исследователями (Queiros et al., 2018). Возможным объяснением является разная теоретическая направленность составляющих субшкалу утверждений: три входящих в субшкалу пункта отражают выраженность эмоциональных реакций человека при просмотре фильма, спектакля, чтении книги, 17-й же пункт в большей степени затрагивает понимание и разделение ценностей и эмоций других людей. Как следствие, наличие данного пункта снижает показатели надежности-согласованности субшкалы, что также было замечено проводящими апробацию опросника французскими исследователями (Myszkowski et al., 2017). 1-й вопрос отличается от входящих в субшкалу пунктов своей формулировкой: большинство вопросов содержат слова «стараюсь», «пытаюсь», отражая нацеленность респондента на понимание другого человека, учет его позиции, формулировка же данного вопроса более общая. В результате в силу выявленных рассогласований было решено исключить 17-й и 1-й пункты из русскоязычной версии опросника.

Согласно результатам анализа конвергентной валидности методики, когнитивная эмпатия оказалась положительно связана со всеми субшкалами эмоционального интеллекта, тогда как аффективная эмпатия с большей частью субшкал была связана отрицательно. Субшкалы, по отношению к которым были выявлены отрицательные корреляции, принадлежат шкале Внутриличностного эмоционального интеллекта. Другими словами, повышенной сензитивности человека к чувствам других соответствуют сниженные способности понимать свои собственные эмоции и управлять ими. Наибольший вклад в обнаруженные отрицательные корреляции с аффективной эмпатией внесла входящая в нее субшкала Отзеркаливания эмоций, связь которой 
со сложностями в регуляции собственных эмоций отмечается рядом авторов (Miguel et al., 2017; Di Girolamo et al., 2019). Межличностный же эмоциональный интеллект - субшкалы понимания чужих эмоций и управления ими оказался положительно связан с Чувствительностью к близким. Таким образом, более внимательные к своим друзьям люди оказываются в большей степени способными понимать, что чувствуют другие, и влиять на это.

Как и предполагалось, эмпатия оказалась отрицательно связана с двумя компонентами Темной триады - психопатией и макиавеллизмом. Высоким значениям психопатии соответствуют низкие значения по всем субшкалам эмпатии, кроме Способности к децентрации. Это соотносится с представленным в литературе положением о дефиците аффективной эмпатии при относительно сохранной способности понимать, что думает и чувствует другой, у лиц с выраженными показателями психопатии (Blair, 2005). Обнаруженные между эмпатией и макиавеллизмом связи хорошо иллюстрируют различие двух компонентов когнитивной эмпатии: люди с более высокими показателями по макиавеллизму оказались более способными, но менее склонными к децентрации. Другими словами, определить, что думает и чувствует другой, люди с высокими показателями по макиавеллизму могут, однако прикладывать каких-либо усилий для того, чтобы встать на позицию другого, им не свойственно. Очень слабая отрицательная связь между макиавеллизмом и Общей чувствительностью свидетельствует о пониженной склонности лиц с высокими показателями по макиавеллизму эмоционально втягиваться в события фильма, спектакля или книги. Положительные взаимосвязи Способности к децентрации и Отзеркаливания эмоций с нарциссизмом расходятся с данными о сниженных эмпатических способностях лиц с высокими показателями нарциссизма (Jonason et al., 2013). Возможно, это связано с формулировками утверждений опросника («Я быстро понимаю ...», «Я легко определяю ...»), которые могут провоцировать высоко оценивающие свои интеллектуальные способности нарциссические личности выбирать более социально желательный вариант ответа.

В отличие от результатов Р. Реньерс с соавт. (Reniers et al., 2011) на нашей выборке в показателях когнитивной эмпатии не было обнаружено гендерных различий, лишь значения аффективной эмпатии у женщин оказались значимо выше, чем у мужчин. Схожий результат наблюдался при апробации на русскоязычной выборке опросника М. Дэвиса (Карягина и др., 2013), где также значимых гендерных различий в способности к децентрации обнаружено не было, хотя в оригинальном исследовании они присутствовали. В обоих случаях наблюдается сильный количественный перевес респондентов женского пола, возможно, это могло сказаться на результатах.

Наше исследование не лишено ограничений. Одним из них является упомянутый выше количественный перевес респондентов женского пола, что, в свою очередь, могло несколько исказить полученные нами результаты. Другим ограничением является достаточно скромный набор методик, использованных для проверки конвергентной валидности опросника. Как мы упоминали ранее, это связано с тем, что при создании QCAЕ использовались вопро- 
сы из EQ и IRI - двух доступных отечественным исследователям опросников, психометрические показатели которых не вызывают вопросов, что делает невозможным включение их в набор методик для проверки конвергентной валидности. Ценным дополнением нашего исследования также было бы включение инструментов измерения эмпатических способностей, не базирующихся на самоотчете респондентов.

Несмотря на упомянутые ограничения, нам удалось реализовать поставленные нами задачи и достигнуть цели нашего исследования. Анализ психометрических характеристик русскоязычной версии Опросника когнитивной и аффективной эмпатии позволяет сделать вывод о том, что это надежный и валидный инструмент, который может быть использован для измерения эмпатических способностей на русскоязычной выборке. Представленная в оригинальном исследовании факторная структура была верифицирована, надежность и конвергентная валидность шкал продемонстрированы. Русскоязычная версия «Опросника когнитивной и аффективной эмпатии» расширяет возможности практической и исследовательской деятельности, в том числе проведения кросс-культурных исследований.

\section{Литература}

Карягина, Т. Д., Будаговская, Н. А., Дубровская, С. В. (2013). Адаптация многофакторного опросника эмпатии М. Дэвиса. Консультативная психология и психотерапия, 21(1), 202-227.

Карягина, Т. Д., Придачук, М. А. (2017). Эмпатически обусловленный дистресс и возможности его диагностики. Консультативная психология и психотерапия, 25(2), 8-38.

Корнилова, Т. В., Корнилов, С. А., Чумакова, М. А., Талмач, М. С. (2015). Методика диагностики личностных черт «Темной триады»: апробация опросника «Темная дюжина». Психологический журнал, 36(2), 99-112.

Люсин, Д., Ушаков, Д. (ред.). (2009). Социальный и эмоциональный интеллект: От процессов к измерениям. М.: Изд-во «Институт психологии РАН».

Ссылки на зарубежные источники см. в разделе References.

\section{References}

Baldner, C., \& McGinley, J. J. (2014). Correlational and exploratory factor analyses (EFA) of commonly used empathy questionnaires: New insights. Motivation and Emotion, 38(5), 727-744.

Banissy, M. J., Kanai, R., Walsh, V., \& Rees, G. (2012). Inter-individual differences in empathy are reflected in human brain structure. NeuroImage, 62(3), 2034-2039.

Baron-Cohen, S., \& Wheelwright, S. (2004). The empathy quotient: an investigation of adults with Asperger syndrome or high functioning autism, and normal sex differences. Journal of Autism and Developmental Disorders, 34(2), 163-175.

Blair, R. J. R. (2005). Responding to the emotions of others: Dissociating forms of empathy through the study of typical and psychiatric populations. Consciousness and Cognition, 14(4), 698-718. 
Davis, M. H. (1983). Measuring individual differences in empathy: Evidence for a multidimensional approach. Journal of Personality and Social Psychology, 44(1), 113-126.

Di Girolamo, M., Giromini, L., Winters, C. L., Serie, C. M., \& de Ruiter, C. (2019). The questionnaire of cognitive and affective empathy: a comparison between paper-and-pencil versus online formats in Italian samples. Journal of Personality Assessment, 101(2), 159-170.

Eisenberg, N., \& Miller, P. A. (1987). The relation of empathy to prosocial and related behaviors. Psychological Bulletin, 101(1), 91-119.

Eres, R., Decety, J., Louis, W. R., \& Molenberghs, P. (2015). Individual differences in local gray matter density are associated with differences in affective and cognitive empathy. NeuroImage, 117, 305-310.

Giromini, L., de Campora, G., Brusadelli, E., D’Onofrio, E., Zennaro, A., Zavattini, G. C., \& Lang, M. (2016). Validity and reliability of the interpersonal competence questionnaire: Empirical evidence from an Italian study. Journal of Psychopathology and Behavioral Assessment, 38(1), 113-123.

Graziano, W. G., \& Eisenberg, N. (1997). Agreeableness: A dimension of personality. In R. Hogan, J. A. Johnson, \& S. R. Briggs (Eds.), Handbook of personality psychology (pp. 795-824). Academic Press.

Hu, L. T., \& Bentler, P. M. (1999). Cutoff criteria for fit indexes in covariance structure analysis: Conventional criteria versus new alternatives. Structural Equation Modeling: a Multidisciplinary Journal, 6(1), 1-55.

Jolliffe, D., \& Farrington, D. P. (2004). Empathy and offending: A systematic review and meta-analysis. Aggression and Violent Behavior, 9(5), 441-476.

Jonason, P. K., \& Webster, G. D. (2010). The dirty dozen: A concise measure of the dark triad. Psychological assessment, 22(2), 420-432.

Jonason, P. K., Lyons, M., Bethell, E. J., \& Ross, R. (2013). Different routes to limited empathy in the sexes: Examining the links between the Dark Triad and empathy. Personality and Individual Differences, 54(5), 572-576.

Jones, A. P., Happé, F. G., Gilbert, F., Burnett, S., \& Viding, E. (2010). Feeling, caring, knowing: different types of empathy deficit in boys with psychopathic tendencies and autism spectrum disorder. Journal of Child Psychology and Psychiatry, 51(11), 1188-1197.

Karyagina, T. D., \& Pridachuk, M. A. (2017). Empathically caused distress and the possibilities of its diagnostics. Konsul'tativnaya Psikhologiya i Psikhoterapiya [Counseling Psychology and Psychotherapy], 25(2), 8-38. (in Russian)

Karyagina, T. D., Budagovskaya, N. A., \& Dubrovskaya, S. V. (2013). Adaptation of multyafactor questionnaire empathy M. Davis. Konsul'tativnaya Psikhologiya i Psikhoterapiya [Counseling Psychology and Psychotherapy], 21(1), 202-227. (in Russian)

Kellett, J. B., Humphrey, R. H., \& Sleeth, R. G. (2006). Empathy and the emergence of task and relations leaders. The Leadership Quarterly, 17(2), 146-162.

Kogler, L., Müller, V. I., Werminghausen, E., Eickhoff, S. B., \& Derntl, B. (2020). Do I feel or do I know? Neuroimaging meta-analyses on the multiple facets of empathy. Cortex, 129, 341-355. https://doi.org/10.1016/j.cortex.2020.04.031

Kornilova, T. V., Kornilov, S. A., Chumakova, M. A., \& Talmach, M. S. (2015). The Dark Triad personality traits measure: Approbation of the Dirty Dozen questionnaire. Psikhologicheskiy Zhurnal, 36(2), 99-112. (in Russian)

Kosonogov, V. (2014). The psychometric properties of the Russian version of the empathy quotient. Psychology in Russia: State of the Art, 7(1), 96-104. https://doi.org/10.11621/pir.2014.0110

Lee, K. H., Farrow, T. F. D., Spence, S. A., \& Woodruff, P. W. R. (2004). Social cognition, brain networks and schizophrenia. Psychological Medicine, 34(3), 391-400. 
Liang, Y. S., Yang, H. X., Ma, Y. T., Lui, S. S., Cheung, E. F., Wang, Y., \& Chan, R. C. (2019). Validation and extension of the questionnaire of cognitive and affective empathy in the Chinese setting. PsyCh Journal, 8(4), 439-448. https://doi.org/10.1002/pchj.281

Lockwood, P. L., Seara-Cardoso, A., \& Viding, E. (2014). Emotion regulation moderates the association between empathy and prosocial behavior. PLoS ONE, 9(5), Article e96555.

Lyusin, D., \& Ushakov, D. (Eds.). (2009). Sotsial'nyi i emotsional'nyi intellekt: ot protsessov $k$ izmereniyam [Social and emotional intelligence: From processes to measurements]. Moscow: Institute of Psychology of the RAS.

Miguel, F. K., Giromini, L., Colombarolli, M. S., Zuanazzi, A. C., \& Zennaro, A. (2017). A Brazilian investigation of the 36 and 16 item Difficulties in Emotion Regulation Scales. Journal of Clinical Psychology, 73(9), 1146-1159.

Miller, P. A., \& Eisenberg, N. (1988). The relation of empathy to aggressive and externalizing/antisocial behavior. Psychological Bulletin, 103(3), 324-344. https://doi.org/10.1037/00332909.103.3.324

Myszkowski, N., Brunet-Gouet, E., Roux, P., Robieux, L., Malŭzieux, A., Boujut, E., \& Zenasni, F. (2017). Is the Questionnaire of Cognitive and Affective Empathy measuring two or five dimensions? Evidence in a French sample. Psychiatry Research, 255, 292-296.

Queirys, A., Fernandes, E., Reniers, R., Sampaio, A., Coutinho, J., \& Seara-Cardoso, A. (2018). Psychometric properties of the questionnaire of cognitive and affective empathy in a Portuguese sample. PLoS ONE, 13(6), Article e0197755.

Reniers, R. L., Corcoran, R., Drake, R., Shryane, N. M., \& Völlm, B. A. (2011). The QCAE: A questionnaire of cognitive and affective empathy. Journal of Personality Assessment, 93(1), 84-95.

Rueda, P., Fernández-Berrocal, P., \& Baron-Cohen, S. (2015). Dissociation between cognitive and affective empathy in youth with Asperger Syndrome. European Journal of Developmental Psychology, 12(1), 85-98.

Seara-Cardoso, A., Neumann, C., Roiser, J., McCrory, E., \& Viding, E. (2012). Investigating associations between empathy, morality and psychopathic personality traits in the general population. Personality and Individual Differences, 52(1), 67-71.

Uribe, C., Puig-Davi, A., Abos, A., Baggio, H. C., Junque, C., \& Segura, B. (2019). Neuroanatomical and functional correlates of cognitive and affective empathy in young healthy adults. Frontiers in Behavioral Neuroscience, 13, 85.

Watkins, D. (1989). The role of confirmatory factor analysis in cross-cultural research. International Journal of Psychology, 24(6), 685-701. 


\section{Опросник когнитивной и аффективной эмпатии}

Приложение 1

Инструкция. Пожалуйста, оцените степень своего согласия с каждым из приведенных утверждений, используя шкалу от 1 (Полностью не согласен) до 4 (Полностью согласен). Для каждого утверждения обведите соответствующую цифру.

\begin{tabular}{|c|c|c|c|c|c|}
\hline & & $\begin{array}{l}\text { Полностью } \\
\text { не согласен }\end{array}$ & $\begin{array}{c}\text { Скорее не } \\
\text { согласен }\end{array}$ & $\begin{array}{c}\text { Скорее } \\
\text { согласен }\end{array}$ & $\begin{array}{c}\text { Полностью } \\
\text { согласен }\end{array}$ \\
\hline 1 & $\begin{array}{l}\text { При просмотре фильма или спектак- } \\
\text { ля мне обычно удается оставаться } \\
\text { объективным, я редко полностью } \\
\text { погружаюсь в происходящее }\end{array}$ & 1 & 2 & 3 & 4 \\
\hline 2 & $\begin{array}{l}\text { Я стараюсь посмотреть на разногла- } \\
\text { сие с точки зрения каждого участни- } \\
\text { ка, прежде чем принять решение }\end{array}$ & 1 & 2 & 3 & 4 \\
\hline 3 & $\begin{array}{l}\text { Иногда я пытаюсь лучше понять } \\
\text { своих друзей, представляя, как все } \\
\text { выглядит с их точки зрения }\end{array}$ & 1 & 2 & 3 & 4 \\
\hline 4 & $\begin{array}{l}\text { Когда меня кто-то расстраивает, я } \\
\text { стараюсь поставить себя на его } \\
\text { место }\end{array}$ & 1 & 2 & 3 & 4 \\
\hline 5 & $\begin{array}{l}\text { Прежде чем кого-то критиковать, я } \\
\text { пытаюсь представить, как бы я себя } \\
\text { чувствовал(а) на его месте }\end{array}$ & 1 & 2 & 3 & 4 \\
\hline 6 & $\begin{array}{l}\text { Я часто эмоционально втягиваюсь в } \\
\text { проблемы моих друзей }\end{array}$ & 1 & 2 & 3 & 4 \\
\hline 7 & $\begin{array}{l}\text { Когда люди вокруг нервничают, я } \\
\text { тоже начинаю нервничать }\end{array}$ & 1 & 2 & 3 & 4 \\
\hline 8 & $\begin{array}{l}\text { Окружающие меня люди сильно } \\
\text { влияют на мое настроение }\end{array}$ & 1 & 2 & 3 & 4 \\
\hline 9 & $\begin{array}{l}\text { Я не могу остаться равнодушным(ой), } \\
\text { если кто-то из моих друзей выгля- } \\
\text { дит расстроенным }\end{array}$ & 1 & 2 & 3 & 4 \\
\hline 10 & $\begin{array}{l}\text { Я часто эмоционально втягиваюсь в } \\
\text { переживания героя фильма, спек- } \\
\text { такля или книги }\end{array}$ & 1 & 2 & 3 & 4 \\
\hline 11 & $\begin{array}{l}\text { Я очень расстраиваюсь, когда вижу, } \\
\text { как кто-то плачет }\end{array}$ & 1 & 2 & 3 & 4 \\
\hline 12 & $\begin{array}{l}\text { Мне радостно в веселой компании и } \\
\text { грустно, когда все вокруг хмурые }\end{array}$ & 1 & 2 & 3 & 4 \\
\hline 13 & $\begin{array}{l}\text { Меня беспокоит, когда другие вол- } \\
\text { нуются и паникуют }\end{array}$ & 1 & 2 & 3 & 4 \\
\hline 14 & $\begin{array}{l}\text { Я легко могу сказать, хочет ли кто-то } \\
\text { еще присоединиться к беседе }\end{array}$ & 1 & 2 & 3 & 4 \\
\hline 15 & $\begin{array}{l}\text { Я быстро понимаю, когда человек } \\
\text { говорит одно, но имеет в виду другое }\end{array}$ & 1 & 2 & 3 & 4 \\
\hline
\end{tabular}




\begin{tabular}{|c|c|c|c|c|c|}
\hline & & $\begin{array}{l}\text { Полностью } \\
\text { не согласен }\end{array}$ & $\begin{array}{l}\text { Скорее не } \\
\text { согласен }\end{array}$ & $\begin{array}{c}\text { Скорее } \\
\text { согласен }\end{array}$ & $\begin{array}{c}\text { Полностью } \\
\text { согласен }\end{array}$ \\
\hline 16 & $\begin{array}{l}\text { Мне легко поставить себя на место } \\
\text { другого человека }\end{array}$ & 1 & 2 & 3 & 4 \\
\hline 17 & $\begin{array}{l}\text { Я хорошо предугадываю, что почув- } \\
\text { ствует другой человек }\end{array}$ & 1 & 2 & 3 & 4 \\
\hline 18 & $\begin{array}{l}\text { Я быстро замечаю, когда кто-то в груп- } \\
\text { пе чувствует себя неловко или неком- } \\
\text { фортно }\end{array}$ & 1 & 2 & 3 & 4 \\
\hline 19 & $\begin{array}{l}\text { По словам других людей, я хорошо } \\
\text { определяю, что они чувствуют и о чем } \\
\text { думают }\end{array}$ & 1 & 2 & 3 & 4 \\
\hline 20 & $\begin{array}{l}\text { Я легко могу сказать, интересно чело- } \\
\text { веку то, что я говорю, или нет }\end{array}$ & 1 & 2 & 3 & 4 \\
\hline 21 & $\begin{array}{l}\text { Друзья делятся со мной своими про- } \\
\text { блемами, так как, по их словам, я очень } \\
\text { понимающий(ая) }\end{array}$ & 1 & 2 & 3 & 4 \\
\hline 22 & $\begin{array}{l}\text { Я чувствую, если мешаю, даже если } \\
\text { другой человек мне об этом не говорит }\end{array}$ & 1 & 2 & 3 & 4 \\
\hline 23 & $\begin{array}{l}\text { Я легко могу определить, о чем может } \\
\text { захотеть поговорить другой человек }\end{array}$ & 1 & 2 & 3 & 4 \\
\hline 24 & $\begin{array}{l}\text { Я вижу, когда кто-то скрывает свои } \\
\text { настоящие эмоции }\end{array}$ & 1 & 2 & 3 & 4 \\
\hline 25 & $\begin{array}{l}\text { Я хорошо предугадываю, как поступит } \\
\text { другой человек }\end{array}$ & 1 & 2 & 3 & 4 \\
\hline 26 & $\begin{array}{l}\text { Обычно я могу оценить точку зрения } \\
\text { другого, даже если я с ней не согла- } \\
\text { сен(на) }\end{array}$ & 1 & 2 & 3 & 4 \\
\hline 27 & $\begin{array}{l}\text { Обычно при просмотре фильма я } \\
\text { остаюсь эмоционально отстраненным }\end{array}$ & 1 & 2 & 3 & 4 \\
\hline 28 & $\begin{array}{l}\text { Я всегда стараюсь учитывать чувства } \\
\text { других, прежде чем что-либо сделать }\end{array}$ & 1 & 2 & 3 & 4 \\
\hline 29 & $\begin{array}{l}\text { Прежде чем что-либо сделать, я ста- } \\
\text { раюсь принять во внимание то, как на } \\
\text { это отреагируют мои друзья }\end{array}$ & 1 & 2 & 3 & 4 \\
\hline
\end{tabular}

\section{Ключ}

\section{Когнитивная эмпатия:}

Способность к децентрации: 14, 15, 17, 18, 19, 20, 22, 23, 24, 25

Склонность к децентрации: 2, 3, 4, 5, 16, 26, 28, 29

\section{Аффективная эмпатия:}

Отзеркаливание эмоций: 7, 8, 12, 13

Чувствительность к близким: $6,9,11,21$

Общая чувствительность: 1(-), 10, 27(-) 